\title{
FOLLOWING EARLY CAREER CHEMISTRY TEACHERS: THE DEVELOPMENT OF PEDAGOGICAL CONTENT KNOWLEDGE FROM PRE-SERVICE TO A PROFESSIONAL TEACHER
}

\begin{abstract}
In this study the aim was to investigate the development of Pedagogical Content Knowledge (PCK) of early career chemistry teachers. Two pre-service chemistry teachers were followed during a one-semester course and after a three-year period as formal high school teachers. The data involved teachers' writings, recordings of lessons and reflections during the course. After three years, the same content lessons in an actual school environment were videotaped. The teachers were then interviewed using the videotapes for stimulated recall. The instruments Content Representation (CoRe) and Pedagogical and Professional-experience Repertoires (PaP-eR's) were used to document and to describe teachers' PCK. Analysis of discursive interaction patterns was performed during lessons. Data analysis was based on the components of teacher knowledge as described in the Morine-Dershimer Model. The development of PCK was enhanced during the pre-service teacher education through the experiences of planning and conducting interventions in the classroom and particularly during the reflection-on-action activities. Results after three years of professional experience revealed an improvement in these teachers' $P C K$ and highlighted the central role of the reflection process and practical experience. From the analysis carried out, it emphasized the need to act in these early years of professional experience through collaborative groups, supporting the reflection process and aiming to contribute more directly to the development of teachers'PCK.
\end{abstract}

Key words: pedagogical content knowledge, teacher's knowledge, teacher's professional development.

\section{Introduction}

The last three decades of research about teacher training produced significant contributions to this field and revealed the importance of the interaction between theory and practice in teacher professional development. A number of authors have concluded on the importance of studying the types of knowledge that is necessary for the development of teacher's professional practice. (Cochran-Smith, 2001; Cochran-Smith, Litle, 1993; Cochran, Deruiter, King, 1993; Shulman, 1987; Orland-Barak, Yinon, 2007; van Driel, de Jong, Verloop, 2002; van Driel, Verloop, de Vos, 1998; Wilson, Shulman, Richert, 1987).

The term Pedagogical Content Knowledge (PCK), originally proposed by Shulman, is related to a set of knowledge that go beyond specific content, including forms of representations on the content and its selection, the exemplifications and analogies, the teaching methodology that may or may not foster meaningful learning this or that content.

When considering the specific content of the discussions, Shulman (1986) proposes this 
Gildo GIROTTO JÚNIOR, Carmen FERNANDEZ. Following Early Career Chemistry Teachers: The Development of Pedagogical Content Knowledge from Pre-service to a Professional Teacher

PROBLEMS

OF EDUCATION

IN THE $21^{\text {st }}$ CENTURY

Volume 55, 2013

58 term as one of the categories for the teachers' knowledge base. In 1987, Shulman proposes seven categories for knowledge base for teaching:

- Content knowledge;

- General pedagogical knowledge, with special reference to those broad principles and strategies of classroom management and organization that appear to transcend subject matter;

- Curriculum knowledge, with a particular grasp of the materials and programs that serve as "tools of the trade" for teachers;

- Pedagogical content knowledge, that special amalgam of content and pedagogy that is uniquely the province of teachers, their own special form of professional understanding;

- Knowledge of learners and their characteristics;

- Knowledge of educational contexts, ranging from the workings of the group or classroom, the governance and financing of school districts, to the character of communities and cultures; and

- Knowledge of educational ends, purposes, and values, and their philosophical and historical grounds. (Shulman, 1987)

Another contribution of Shulman (1987) was the Model of Pedagogical Reasoning and Action (MPRA, Figure 1), that suggests the processes by which the training and professional development follow. In this model Shulman emphasizes the role of teachers' reflection in the process of professional development.

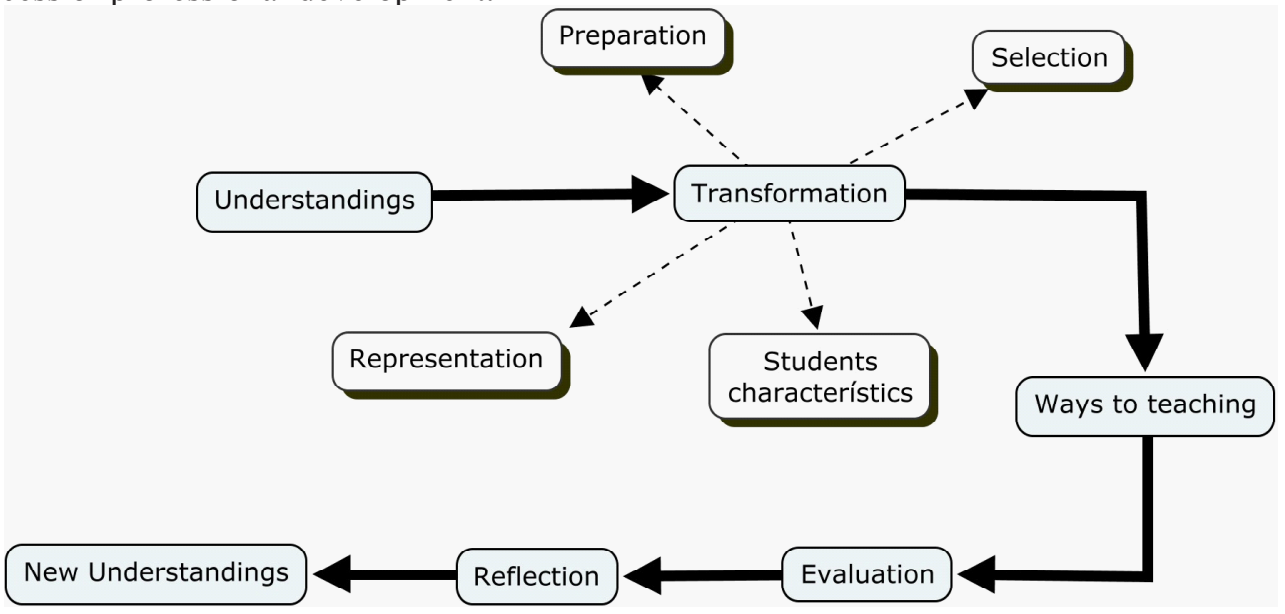

Figure 1: Model of Pedagogical Reasoning and Action (MPRA). Adapted from Shulman (1987).

The concept of knowledge base and PCK has been constantly discussed in the literature on teacher education. For Grossman (1990), PCK is driven by the "conceptions of purposes for teaching subject matter" and it is composed by knowledge of students understandings, curricular knowledge and knowledge of instructional strategies (Figure 2).

Veal and Makinster (1999) define the PCK as the ability to translate the thematic content to a diverse group of students, using strategies and methods of instruction and assessment, taking into account the contextual constraints, cultural and social environment of learning.

According to Loughran, Berry and Mulhall (2006) PCK is the knowledge that teachers develop over the years and through experience, about how to teach a particular content in a particular way in order to gain an understanding of students.

There are also research that aim to study the proposed categories, or other aspects related to PCK, like the aspects of its development through the perception of students (Jang, 2011) and statistical analysis of knowledge (Jang, Guan, Hsieh, 2009), about the construction of new models to interpret the practice and the knowledge base (Friedrichsen, van Driel, Abell, 2006, 2008) and the relationship between subject matter knowledge and pedagogical knowledge (Käpylä, Heikkinen, Asunta, 2009). 
Before the PCK concept and this discussion on how to make the relationship between

PROBLEMS

OF EDUCATION

IN THE $21^{\text {st }}$ CENTURY

Volume 55, 2013

the content and pedagogical aspects, and also how this process occurs, some research has been undertaken in order to investigate the nature of this teacher's professional knowledge. Such surveys include models that grouped categories of knowledge related to professional knowledge.

Several models of professional development have been created during the last two decades. These models often use complementary categories of knowledge base from Shulman, sometimes with addition, sometimes with subtraction and sometimes include different categories. In these models, the researchers seek to link the categories and think about a sequence of events, in other words, seek to understand the professional development and how and when the categories of knowledge are present in this process.

Grossman (1990) states that "while researchers differ in their definitions of various components, four general areas of teacher knowledge can be seen as cornerstones of the emerging work on professional knowledge for teaching: subject matter knowledge, general pedagogical knowledge, pedagogical content knowledge and knowledge of the context". She systematized a model of teacher knowledge where these components are defined (Figure 2).

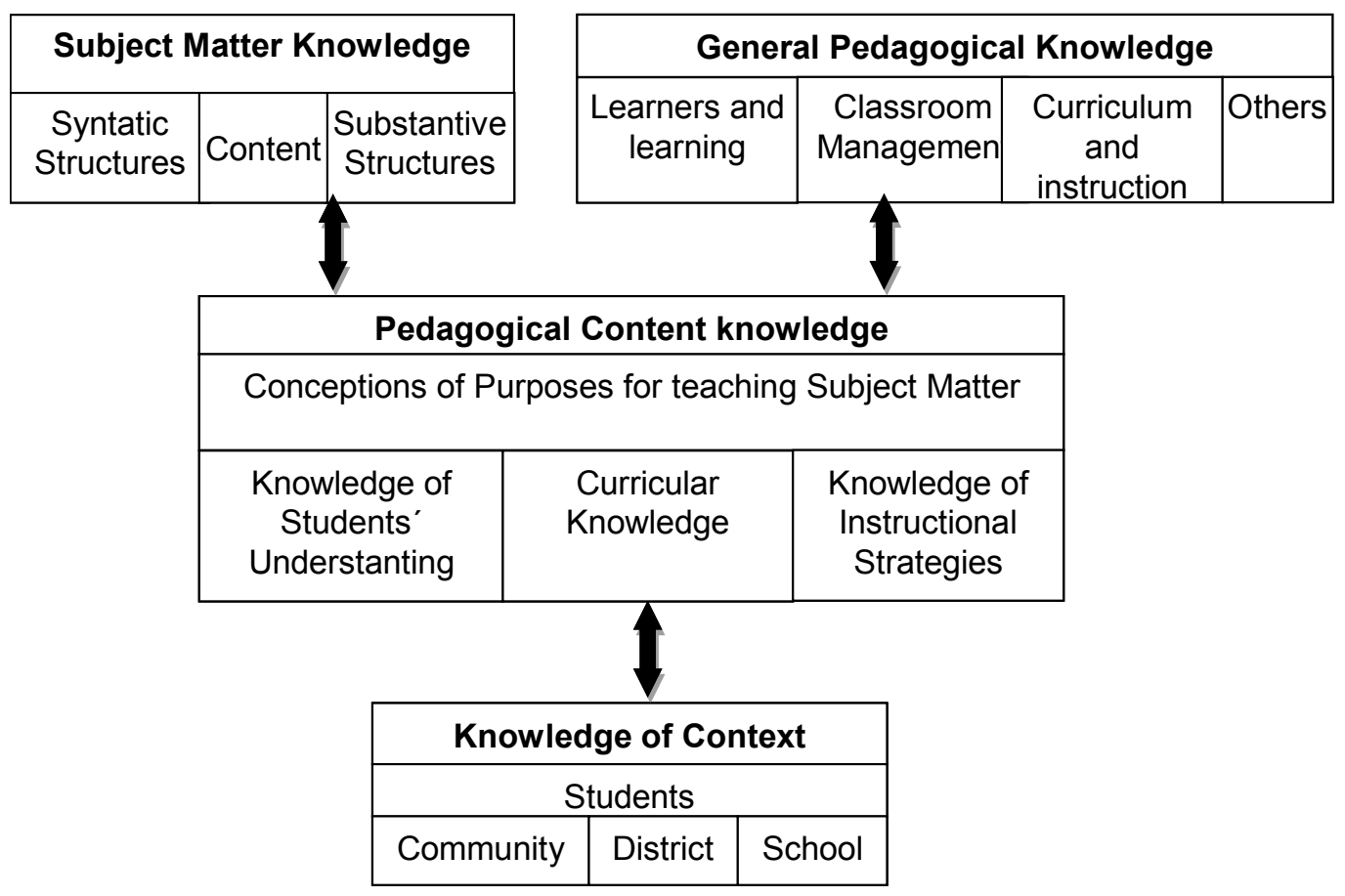

Figure 2: Model of Teacher Knowledge (Grossman, 1990).

Morine-Dershimer and Kent (1999) present an inclusive model relating the knowledge involved in the development of teachers' PCK, and their relationships. In the Figure 3 is shown the interpretation of these authors about the place of pedagogical knowledge in relation to the full set of categories of teacher knowledge identified by Shulman (1987). In the Figure 4 is shown the conception of the authors related to various facets of pedagogical knowledge that have been informed by recent research on teaching.

These authors (Morine-Dershimer \& Kent, 1999) point out that identifying these knowledge during a class, or during an activity of reflection on practice may supply us to better understand the development of PCK.

Given the above and collaborating with different approaches related to professional knowledge, the aim of this study is to promote an analysis in order to recognize aspects of the development of PCK. Using tools already developed in the literature, such as models that seek 
Gildo GIROTTO JÚNIOR, Carmen FERNANDEZ. Following Early Career Chemistry Teachers: The Development of Pedagogical Content Knowledge from Pre-service to a Professional Teacher

PROBLEMS

OF EDUCATION

IN THE $21^{\text {st }}$ CENTURY Volume 55, 2013

to relate categories of knowledge and actions, the development of PCK of two early career chemistry teachers was analyzed.

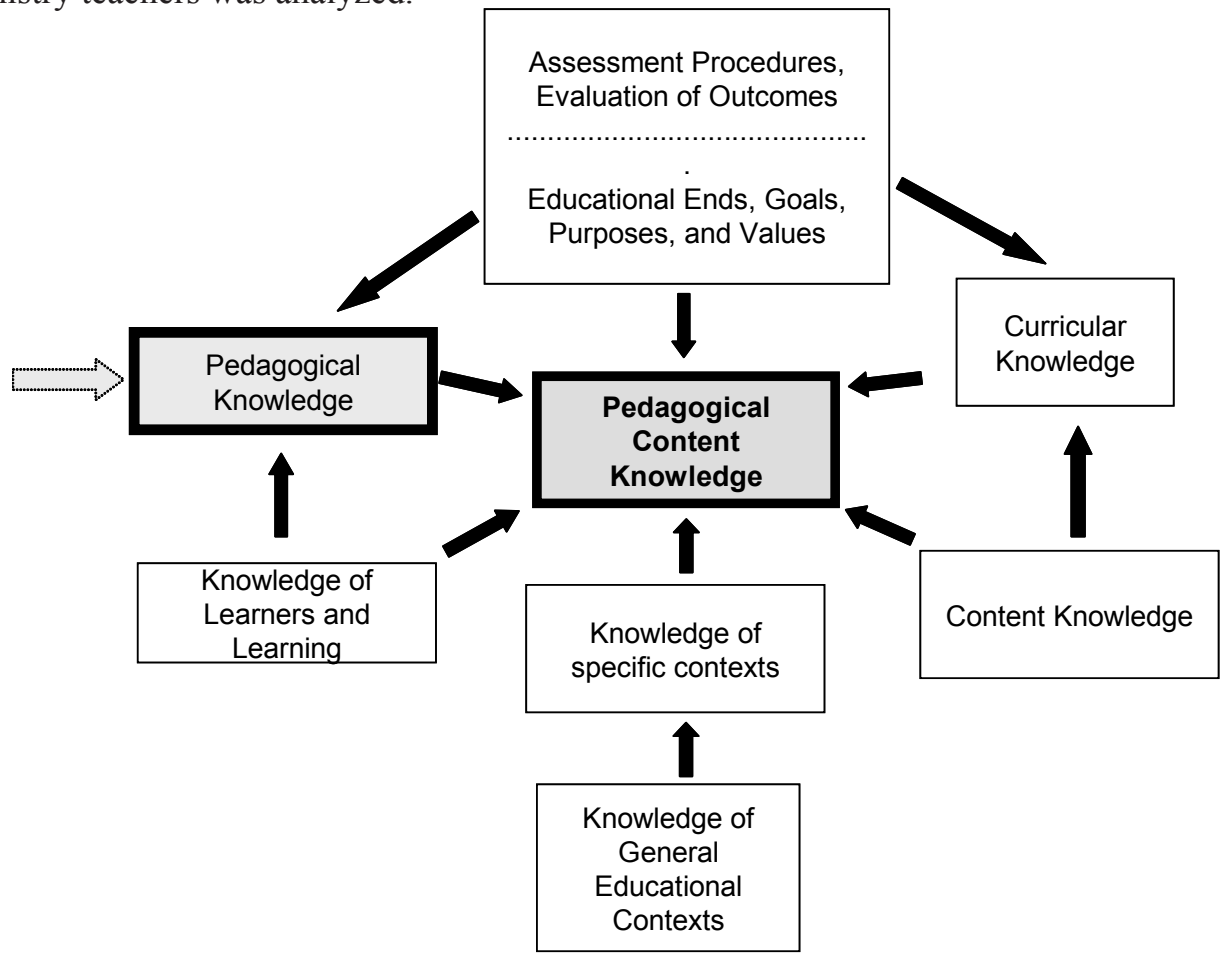

Figure 3: Categories contributing to Pedagogical Content Knowledge (MorineDershimer \& Kent, 1999).

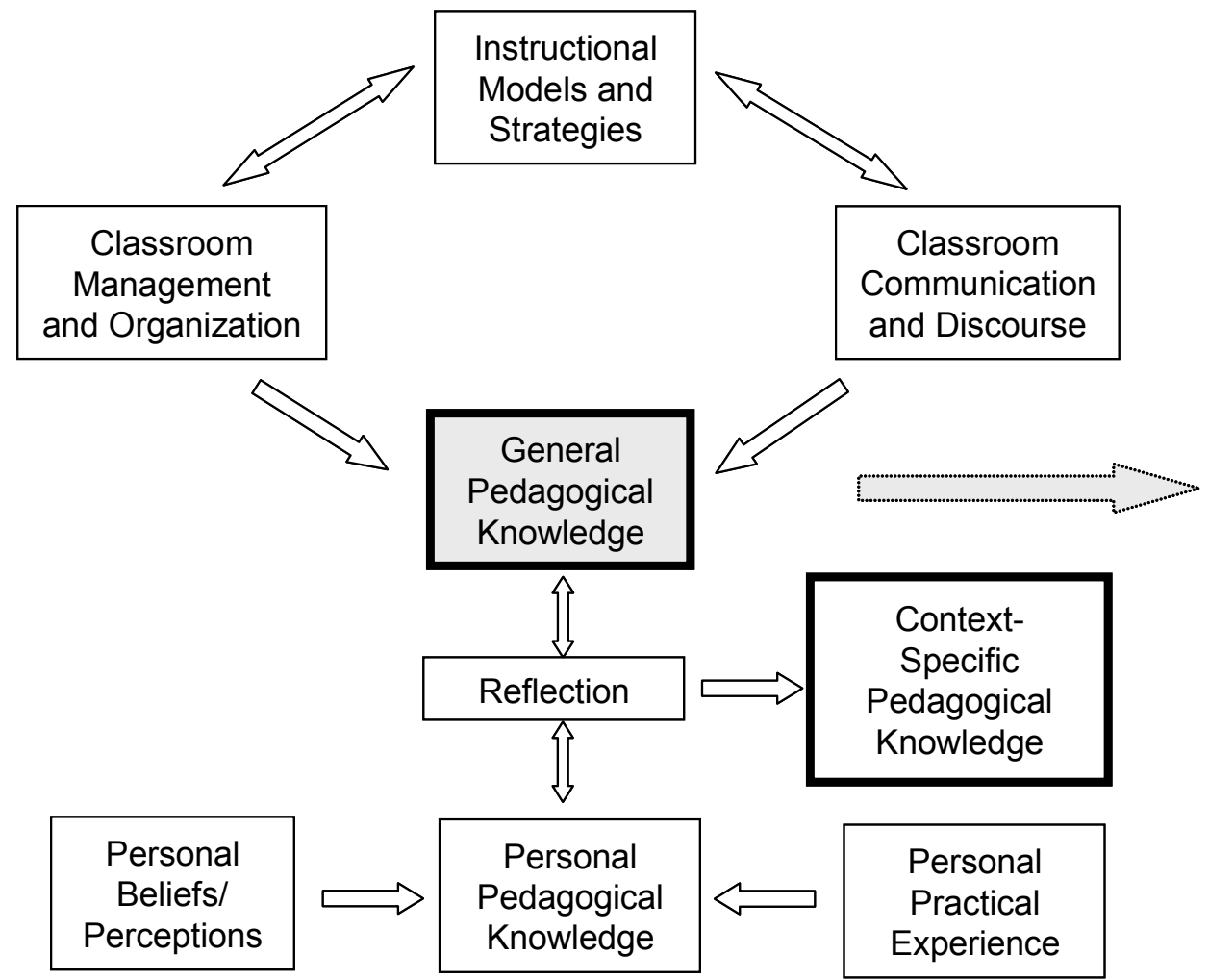

Figure 4: Facets of Pedagogical Knowledge (Morine-Dershimer \& Kent, 1999). 


\section{Problem of Research}

Even though the literature points out some specific knowledge that is necessary for teachers in the classroom, novice teachers only have this knowledge derived from theory. It is during the first years as professional teachers that they put this knowledge into action developing the initial pedagogical content knowledge. In this paper two chemistry teacher's PCK were followed from initial training (pre-service) till a period of three years of experience as professional teachers (in-service) and their PCK development was documented.

More specifically, the aims of the study are:

i.) Investigate PCK development of two Chemistry teachers from two different moments: first when they were pre-service teachers trained at University of São Paulo and after three years when they are working as teachers in high school level.

ii.) Look for evidences how the initial training and initial teaching experiences created possibilities for such PCK development.

\section{Methodology of Research}

The participants were two current in-service chemistry teachers (T1 and T2) who were pre-service chemistry teachers at the University of São Paulo. Thus, the intention was to analyze the same teachers in two different moments of professional development (Figure 5).

During training these teachers attended, among others, a discipline called "Methodology for Chemistry Teaching". This course aims to help student-teachers to plan and conduct an experimental class. The pre-service chemistry teachers realized a lesson plan and during the classes taught was performed the audiovisual recording for later analyses and reflection. These classes, in general, were performed with groups of two to three undergraduates (Girotto-Junior, 2011). After three years for $T 1$ and two years and a half for $T 2$ in which these teachers acted professionally, the same data (lesson planning, audiovisual recording, interview and stimulated recall) were collected about same content to compare and analyze eventual changes (Figure $5)$.

During the period data was collected T1 taught in the course "General Chemistry" to first year students graduate at a private university in the S?o Paulo city. The purpose of this course was to review the concepts learned in high school and promote learning for students with deficits in these contents. T2 taught at a public school in the city of Barueri in the state of São Paulo to students in the first year of high school. Both schools had an adequate structure in terms of laboratories and libraries, and in both cases the number of students in class was between 30 and 40 students.

The instruments developed by Loughran; Mulhall and Berry $(2004 ; 2006)$ named CoRe (Content Representation) and PaP-eRs (Pedagogical and Professional experience Repertoires) were used to document the pedagogical practices and to describe these teacher's PCK. Also the analytical tool of discoursive interaction patterns from Mortimer and Scott (2002) was used to analyze the lessons both during their pre-service programs and during in-service classes to identify possible changes in the teaching approaches and interaction patterns.

The data collected for this analysis included the lesson planning and videotapes of the teachers' classes during their pre-service program and the actual lesson planning and recordings of the actual classes currently taught by the same teachers on the same subject matter. The teachers were later interviewed using the videotapes for stimulated recall (Nilsson, 2008). In the Figure 5 is represented the moments in which data were collected and way of analysis.

Data analysis was based on the components of teacher knowledge from the Morine Dershimer and Kent model (1999) presented in the Figures 3 and 4, and some aspects of the teacher discourse were related to the Model of Pedagogical Reasoning and Action proposed by Shulman (1987), already presented at Figure 1. 
Gildo GIROTTO JÚNIOR, Carmen FERNANDEZ. Following Early Career Chemistry Teachers: The Development of Pedagogical Content Knowledge from Pre-service to a Professional Teacher

CATS

OF EDUCATION

IN THE $21^{\text {st }}$ CENTURY

Volume 55,2013

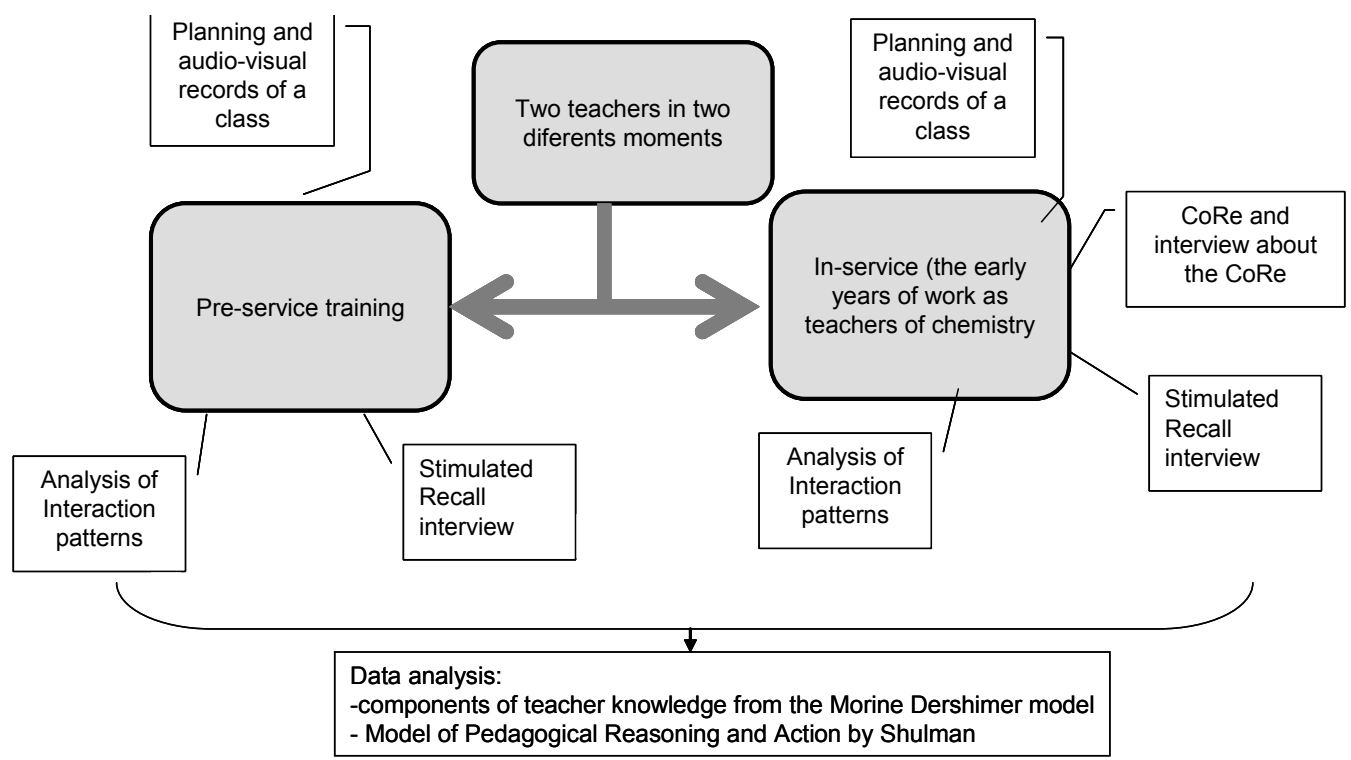

Figure 5: Representation of data collected and analysis from two novice teachers teaching the same content in two professional moments: pre-service and in-service during early career experiences.

\section{Results of Research}

The results reported in this study refer to the two teachers (T1 and T2) which, as previously mentioned, were pre-service teachers and attended the discipline Methodology for Chemistry Teaching and currently work as teachers at different schools (described in the following items) .

\section{Results for Teacher 1 (T1)}

Teacher 1, during the period of data collection worked as Chemistry teacher at a private university in São Paulo city, Brasil, teaching some subjects, among which "General Chemistry" for a Biomedical Sciences' course. The goals of the course were to review basic concepts of chemistry and prepare students to other disciplines such as biochemistry and analytical chemistry. T1 had previous experience as a high school teacher in the São Paulo city.

\section{Teacher's intention - class at training course}

T1 planned the lesson during the Methodological course at initial training in order to perform the reading and discussion of a text, making a sequence consisting of 12 experiments on the theme "Physical and Chemical Transformations" and the discussion of the results of each experiment. The total time class was 150 minutes. The analysis of the lesson plan shows that the teacher had as goal and justification: "Identifying properties of the systems that facilitate the recognition of the chemical transformations' occurrence." According to T1, the theme was chosen because "it is an issue of fundamental importance to the beginning of chemistry" study". During the interviews, the teacher also mentions that: 
[...] we really liked the idea of developing skills and abilities, so based on that, we thought to use the curriculum material from Gepeq ${ }^{1}$, then the starting point would be an experiment, or would be a suggestion of an experiment from the Gepeq's book, because this is a material that enhances skills development. The idea was to develop skills in students, in terms of organizing data in a table, collect, come to some conclusion. They were first year high school students, so it had to be something really very preliminary. (T1 interview)

During the interviews, T1 cites excerpts in which what was thought did not occur as it expected. In addition to the above described the teacher says:

[...] The intention was to develop skills and abilities and make a discussion. But when I say make a discussion, it's not in the sense of a monologue of the teacher, but a discussion which begins by students, they talking about, exposing themselves, putting them a point of view to reach a consensus. But when we see the (...) what happened was a monologue (...) was a content delivery. (T1 interview)

The previous sections show that the intention was to develop a dialogic class with the participation of students, in order to develop skills and competencies. The curricular material and method (research by experimentation) were chosen considering this proposal. T1 had the belief that by choosing a curriculum material which was student-centered, the planning and the development of the class would be also student-centered. The video with the class recorded show that it was not the case.

\section{Class Development at training course}

During episodes of class analysis, it was found that the teacher interacted with students considering talking to some of them and seeking dialogue. However, the students' answers did not lead to continuation of the class and the script was discarded. It is noted that there was, in most of the time an interactive approach of authority (Mortimer \& Scott, 2002) where the teacher interacts with students, but considers only those aspects relevant to the objective of the lesson.

Below is it possible to observe the answer of T1 about the strategies used during class:

It is worth mentioning here a mistake committed by our group in regard to conceptions of teaching and learning. At that time we had in mind a constructive or progressive education, one in which there is a dialogic interaction between teacher-student and student-student. So we do not worry about a problem whose resolution, experimentation would give subsidies. (T1 interview)

This was quite evident when (...) when we wanted to make the discussion of the experiments - however, the effect was driven to a presentation of results, not an argument (...) almost like a guessing game. (T1stimulated recall)

In this speech, it is understood that the teacher, even though had theoretical knowledge, failed to apply it the way he expected. This perception has been taken both during class in a pre-service moment and after three years during stimulated recall.

\section{Reflection about pre-service class and planning a new class}

By analysing the class managed during pre-service training, the teacher had perceptions of mistakes and showed the possibilities of changes in future classes. Such perceptions can be illustrated by the following statements extracted from the interview after three years:

About the activities and content:

[..].there were also other factors which were fatigue by excessive number of experiments and the intrinsic difficulty between them (T1 interview after three years)

1 Gepeq is a research group in chemistry Education that developed curriculum material for teaching based on constructivist approach. 
Gildo GIROTTO JÚNIOR, Carmen FERNANDEZ. Following Early Career Chemistry Teachers: The Development of Pedagogical Content Knowledge from Pre-service to a Professional Teacher

PROBLEMS

OF EDUCATION

IN THE $21^{\text {st }}$ CENTURY Volume 55, 2013

64

[...] for the beginner student in chemistry, which does not have a microscopic model for explaining the changes, it is too difficult to interpret the system of sugar and water in an interaction that produces a dissolution of one space into another, instead of a chemical change itself or cobalt chloride system and water in which, although colour change occurs, the evidence of chemical transformation guard ambiguity regarding the case of an interaction that leads to the transformation or not. (T1 interview after three years)

[...] to change with cobalt chloride, from blue to pink there was an impasse, because during the time to test the experiment we did not reflect well on what was happening. The transformation that happens with cobalt chloride - complexation is what happens with water and then it changes from blue to pink. But a complexation is a chemical transformation or it is not a chemical change? It is complicated. [...] For a high school student it is extremely complicated because you have cobalt chloride at the beginning and cobalt chloride at the end, so which is the transformation, transformed what into what? This in my view, it was an experiment that should not be there, thinking now, because it was very difficult "(...) and at the time, we conclude that there was a chemical transformation. (T1 interview after three years)

About a new class:

$[\ldots]$ the class is still structured the same way, but on experimentation involving a small number of experiments and who had some connection with society. It would then attempt a teaching STS. (T1 interview after three years)

\section{T1 still says:}

[...] Could still be introduced auxiliary experiments provided evidence that chemical transformations in solution such as the precipitation of aluminium hydroxide used in water treatment and alcohol test (colour change). (T1 interview after three years)

In reviewing the class video record and asked about the possibility of developing a lecture on the same topic nowadays, the teacher says:

[...]in terms of intentions ... to develop skills and abilities I would continue with this master guide (constructivist perspective), maybe I'd think of something that does not conflict with the idea of skills and abilities, which is the story of cognitive abilities and high/ low order, which I really like, I think it is very interesting and within these criteria, this guideline I would reduce the experiments, the first thing (...) Maybe experiences a bit shorter, simpler, fewer, that were able to meet these key criteria, and make the discussion among students appears, discussion, integration of ideas from them and a conclusion... (T1 interview after three years)

In this excerpt from the stimulated recall interview after three years is shown how experience and subsequent reflection had importance for the improvement of professional practice. When planning the lesson, the teacher does not realize that some aspects could harm the development of the lesson, as the excess on the number of experiments. After "try" to practice and reflect in order to reformulate the same teacher creates new subsidies for future actions. From the data presented and the analyses a summary of the results for T1 is presented in Table 1. At this table important ideas from T1 mentioned during class plannings, interview and stimulated recall interview were compared, as well as both classes managed during pre-service and during in-service experience. 
Table 1. Compilation about T1 results.

\begin{tabular}{lll}
\hline $\begin{array}{l}\text { First Class } \\
\text { Pre-service experience }\end{array}$ & Planning & Class development \\
\hline Reflection 1 & Change the number of experiments & Constructivist proposal with STS approach \\
\hline & & \\
\hline $\begin{array}{l}\text { Class after 3 years } \\
\text { in-service experience } \\
\text { (Reflection 2) }\end{array}$ & $\begin{array}{l}\text { Change and adequacy of the amount of } \\
\text { experiments }\end{array}$ & $\begin{array}{l}\text { Constructivism approach. Proposal based in } \\
\text { HOCS and LOCS }\end{array}$ \\
\hline $\begin{array}{l}\text { Related knowledge } \\
\text { Actions of perception }\end{array}$ & $\begin{array}{l}\text { Knowledge of context/management of } \\
\text { the classroom/experience }\end{array}$ & $\begin{array}{l}\text { Knowledge of teaching and learning concep- } \\
\text { tions / knowledge of students }\end{array}$ \\
\hline
\end{tabular}

From the analysis performed, it is clear, that teacher T1 demonstrated, after three years of experience, distinct perceptions regarding the development of his class during pre-service period. This was possible through the process of observation of his own practice recorded on video, stimulated recall and reflection.

During pre-service training, the teacher $\mathrm{T} 1 \mathrm{had}$ intentions and theoretical knowledge on issues related to educational practice. However, the lack of experience and knowledge of the management of the classroom and the context created difficulties in the development of the class. The initial reflection, held immediately after the intervention performed and the reflection promoted after three years reveals clear differences. After three years of classroom experience, T1 has a better understanding of the problems related to the planning and execution of the lesson, corroborating in part with the theoretical models he had in mind.

For this teacher, the development of skills and knowledge was promoted initially in the pre-service training through the experience of planning a class and carrying out intervention in the classroom and activities that sought to stimulate reflection on the action with the aim of developing PCK. Even though the developing of PCK was initiated during pre-service experience, after three years of classroom management as in-service teacher, T1 shows an improvement in the quality of his reflection. The teacher began to realize things before imperceptible to him and presented new strategies considering such perceptions. After three years of experience in the classroom, the focus moved from simple selection of experiments and content from a constructivist approach' textbook to the selection of experiments and content that takes into account the difficulties of the students and the management of the classroom. Thus, it is clear that there was a significant PCK' development for this teacher during these three years of experience in the classroom.

\section{Results for Teacher 2 (T2)}

T2 had taught to high school level in a municipal school in São Paulo for two years and a half when he was investigated. During pre-service, the lesson taught in the discipline Methodology for Chemistry Teaching had the theme "combustion".

During interviews and analysis of planning with the teacher, he reported that, currently, the subject is not addressed in a specific class, and that appears in the discipline of chemistry in some topics such as "Chemical Transformations". He also reported that the subject, "Chemical Transformations", is covered in a set of three to four 50-minute classes, one class laboratory and the other in the classroom. Thus, we focused our study on this set of lessons. 
Gildo GIROTTO JÚNIOR, Carmen FERNANDEZ. Following Early Career Chemistry Teachers: The Development of Pedagogical Content Knowledge from Pre-service to a Professional Teacher

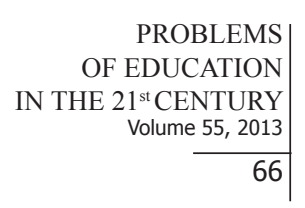

PROBLEMS

$21^{\text {st }}$ CENTURY Volume 55, 2013 66 of initial questions about "Combustion" (Which is? What is necessary to occur? What are the products of combustion?, among others). Then, a practice being carried out by students was to try to blow out a candle using different materials, demonstration experiments to show the soot formation and the participation of oxygen, final questions and ideas in a summary table (in the blackboard).

The plan consisted of a description of the activities to be developed and the questions to be answered during the class. The intention was to develop a class with participation of students in order to enhance students' ideas and from them develop the theme of the lesson, as reported in the following excerpt from the interview:

[..] But one thing we already worried enough that it was already combined was value any involvement, then if the student answered more or less wrong, appreciates the part that is correct "ok, probably what you mean is this, (...) oh, look here, student 1 give a contribution, this point he is calling attention is important" right, this idea of participation to enhance the student feel more comfortable, so he also feels more motivated, magnify a thing he already knows a little. (T2 interview)

\section{Class development at training course}

In the central part of the lesson, the teacher sought to introduce the purpose of the lesson, "what is needed to burn the candle or the factors necessary for the existence of the flame on the candle." For this he adopts the strategy of collecting data obtained by the students in the experimental activity through direct questions.

In general, the teacher considered all the ideas of the students, however, not synthesized, and did not propose an organization what was exposed. The teacher wrote on the blackboard just what was necessary to justify the purpose of the lesson and to continue the lesson plan, which followed an interactive and authoritative approach (Mortimer \& Scott, 2002).

\section{Reflection about pre-service class and planning a new class}

During the interview, $\mathrm{T} 2$ says:

[...] That was something I always did, present a problem, oh let's think about the candle, in the case of the flame. Have you ever stopped to think that the blue flame of the stove is probably hotter than yellow flame? Wow, this is a question outside the context of student. You have to promote a higher motivation. You need to have a goal and then present the questions that help you to solve the problem. So let's think about every detail of how a candle works to understand what is what are the things needed to burn it, for there is fire. So I think it was very common to present short questions that lead to an answer, which leads to a new question, which leads to a new question, which leads to a new question and then you make a resume and say Ok we OK, we understand this. Wow, but that was the goal?. (T2 interview)

He adds:

$[\ldots]$ we do the lesson thinking on the lesson, we develop a lesson plan thinking on giving a good class, you do not think if it is intelligible... if it has a consistency to the students who do not have a knowledge about the subjects, for those who do not know where are you going to get, so I do not remember for example if in the beginning of the class we explained exactly where we planned to get and what was the way we planned to proceed to achieve that result, so today I think it's important I think the student has to know, have to have a preview of where, what is the purpose of the teacher in that class. (T2 interview after two and a half years)

When T2 was questioned if his class was good he mentioned:

For that moment I though it was but, looking to it today it was not good. (T2 interview after two and a half years) 
The excerpts of the interview presented above sought to point the view's teacher about the class at pre-service training, looking for elements that could show his reflection about that class. Still, we sought excerpts in which the teacher evaluated his class, according to his current perspective, after completion of their initial training and after two and a half years of experience as a teacher in high school. The idea was to show how these auto-evaluations were related to professional development, seeking also highlighted aspects of the teacher' speech who might be confronted with their practice.

About the class and the influences of the Chemistry Teaching Methods' course:

[...] In this course, you have a long time to planning just one class, ok? This is very different from the day-to-day classroom where you have there, 26 lessons per week, I don't have a month to prepare each of them. (...) Here (in the course) you have a long time planning, you have time, you have time to go and see the laboratory experiments, (...) It changes, maybe the classes I took before, maybe the classes that I gave after this activity, changes exactly this notion that planning takes time but it enhances the classroom performance because you anticipate problems. (T2 interview)

About the experiment developed in class (students proposed different ways to extinguish a candle), T2 was questioned if he still would use it. At this point the teacher reports:

[...] I do something...I do a more mental experiment. I ask, I light a candle and then ask, in what way we can blow out the candle? And then they think. I do not feel the need for experimentation in everything... hands on experiments, stay 20 minutes, 10 minutes finding ways to extinguish a candle. After the proposes, if they still are with doubts, we tested, right, but so I still do something because I still work quite this idea what it is necessary for extinguish the fire. (T2 interview)

\section{Planning a new class}

As previously reported, T2 does not work anymore the theme "Combustion" in a single class, in contrast he addresses the subject matter along the topic Chemical Transformations that encompasses the principle of conservation of mass (Lavoisier), chemical reactions and later representations of substances in the transformations. Thus, the proposal for the new classes had this focus in mind.

The new class planning presented a structure comprising introduction, previous exercises and experimental script, directing students to prepare for the class and to examine issues previously.

Comparing the two plans, it was found that during the first plan, its constituent parts were not clearly defined, i.e. there was no differentiation between introduction, purpose, approach, evaluation, etc. While in the second plan, these parts were presented clearly defined.

It appears that the objectives of classes (pre- and in-service contexts) were distinct, showing a change of teaching conception of that particular content. However, it was no possible to promote conclusions about the teacher's PCK only analyzing the plans, since other factors might be linked to this change, such as the formalized curriculum that T2 must follow in a real professional performance.

Similarly, it was proceeded as presented in figure 5. The intentions of the teacher with the class were analysed (through planning and CoRe) together with the development of the class. Thus, when analysing the lessons and interviews on these classes it was noticed that the teacher held, generally, the authoritative discourse, directing questions to students and selecting only the answers to achieve the objective of the lesson.

However, it is noted in some activities, which corroborate with the intentions described in the answers to the CoRe. As an example, in the activity regarding the Mass Conservation Principle, the teacher performs with students burning paper and steel wool in a demonstrative way and he adapts a dialogic and authoritative discourse. In respect of the purposes for this experiment, $\mathrm{T} 2$ cites in the CoRe: 
Gildo GIROTTO JÚNIOR, Carmen FERNANDEZ. Following Early Career Chemistry Teachers: The Development of Pedagogical Content Knowledge from Pre-service to a Professional Teacher

PROBLEMS

OF EDUCATION

IN THE $21^{\text {st }}$ CENTURY Volume 55,2013
[...] The idea may seem obvious but the numerical verification is not part of the everyday experience $[\ldots]$

And he added:

[...] Considering the difficulty of measuring the mass of gaseous substances, the real understanding of the mass conservation principle depends on the relationship between experimental data and the representative models...(T2 answer to $\mathrm{CoRe})$

From these lines it was noted that the T2 proposed a teaching strategy that could overcome the difficulty presented. When asked why he thought that the students had such difficulties he answers:

[...] That was reading the responses, it was over the years by reading the texts of students. I was very nervous when before admitting that difficulty was related to language (...) then at some point over time I decided to take that language is a problem within the learning sciences, both the language of words, that they generate confusion when we use, as symbols, as a representation of what we do matters.

His speech clearly showed the influence of professional experience about the knowledge of this teacher, which directly influenced the pedagogical knowledge and consequently the way to plan and promote learning through knowledge of instructional strategies as well as consistency between words, between planned and the practice.

It is noticeable from these results that one of the objectives of the methods course, which was to assist the teacher with the reflection process and with the development of a lesson plan contributed in part to the development of professional practice.

However in high school chemistry lessons of this teacher still prevailed an authoritative discourse, with questions and answers ready in order not to lose the focus of the class and thus preventing the wider reflection from the students.

In the same way it was done for the first teacher, the Table 2 was organized to relate the changes between classes during the pre- and in-service experiences as well as the related knowledge.

Table 2. Compilation about $\mathrm{T} 2$ results.

\begin{tabular}{lll}
\hline & Planning & Class development \\
\hline $\begin{array}{l}\text { First Class } \\
\text { Pre-service experience }\end{array}$ & $\begin{array}{l}\text { Content: combustion } \\
\text { Extensive plans. Too many experiments, activities and } \\
\text { concepts. Without previous exercises }\end{array}$ & $\begin{array}{l}\text { Parts of the planning was } \\
\text { not performed }\end{array}$ \\
\hline Reflection 1 & Change the number of experiments & $\begin{array}{l}\text { Constructivist proposal with } \\
\text { STS approach }\end{array}$ \\
\hline $\begin{array}{l}\text { Class after 2 1/2 years } \\
\text { (Reflection 2) }\end{array}$ & $\begin{array}{l}\text { Content: Chemical transformations and Lavoisier Law. } \\
\text { Division in theory and practice }\end{array}$ & $\begin{array}{l}\text { Proposal partly consistent } \\
\text { with the practice }\end{array}$ \\
\hline Revious tests, inquiry activities & Educational goals, purposes and values. Knowledge of & $\begin{array}{l}\text { Knowledge of teaching } \\
\text { and learning conceptions / } \\
\text { curriculum / communication } \\
\text { and speech }\end{array}$ \\
\hline Actions of perception & Reflection & $\begin{array}{l}\text { Observation and reflection } \\
\text { experience }\end{array}$ \\
\hline
\end{tabular}

Results from teacher T2 revealed some interesting findings. During the pre-service experience $\mathrm{T} 2$ presented intentions related to student participation, and related to the development of 
a lesson with prevalence of dialogic discourse. However, the class did not happen as planned. It was attributed to poor knowledge on the specific context coupled with professional inexperience and the difficulty of establishing the objectives and educational purposes made initially. On the other hand, T2 revealed domain in the subject matter knowledge, knowledge about the strategies and during communication and speech in the classroom. Yet such perceptions were noted by the teacher during the reflective process.

\section{Discussion}

Through the analysis of both the audio-visual records and the interviews, it appears that both teachers, during pre-service training had solid knowledge of the subject matter, and knowledge of teaching strategies. However, both were theoretical knowledge. The teachers knew the content of chemistry and had studied the theories and teaching methodologies, as well as models and teaching strategies for a particular content. However, it is evident that these skills were not applied in the best way when teachers taught the lesson in a real environment of a classroom. The results showed that these teachers failed on the knowledge of the specific context of teaching, the goals and purposes of the educational and professional experience. This conclusion comes from the fact that teachers expressed the desire of having student participation during class, and that the class should have a discussion in order to provide an education with a proposed interactive / dialogic pattern. However, during the practice of both teachers this dialogic interaction did not occurr. Regarding the planning of lessons, for both teachers, lesson plans had an excess number of activities, occurring thereby suppressing actions planned and directing the class to a pattern of authority. In this sense, the discourse and interactions observed in the classroom differed from the models and teaching strategies designed and planned by teachers. For these two teachers, the proposal to systematize the lines / ideas of students through interactive and dialogical activities were not performed. In the first case occurred, according to T1 as a "guessing game" and for the teacher T2 this activity did not occur. When asked about the classes at the pre-service training, teachers 1 and 2 stated that they would restructure the planning. Teacher $\mathrm{T} 1$ first promoted a reduction in the number of experiments and changed some experiments using simpler and that could be better exploited. The teacher $\mathrm{T} 2$ also converged to a change in the lesson plan, which was verified effectively, since there was a restructured class. Both teachers conducted two different initial class planning after three/ two and a half years respectively, and change the way specific content was addressed, ie, the instructional sequence.

The study presented here is echoed in other studies where not only the PCK has been documented, but especially the development of teachers' PCK with the years of experience needs to be documented and analyzed. The idea is to document how teachers can develop PCK by promoting activities during training and professional practice. Williams et al. (2012) designed a study to examine whether the instrument CoRe (the same used here) codesigned by an early career secondary teacher with expert content and pedagogy specialists, could enhance the PCK of early career teachers. Vazquez-Bernal et al. (2012) described a case study of long duration (9 years) that has allowed researchers to gain some insight into how the professional development of a teacher occurs and the underlying obstacles making the processes so slow. They took the professional development of a science teacher as involving the integration of reflection and classroom practice. Oh \& Kim (2013) explored how science content knowledge was pedagogically transformed in Korean elementary classrooms. Data revealed that the Korean teachers often engaged in transforming science content knowledge by means of different semiotic modes, including language, pictures, materials, actions, and their complex combinations. Further, their representations of scientific knowledge were in diverse forms, such as personifications, analogies, quiz questions, pictorial models, diagrams, animations, real-life examples, hand demonstrations, videos, flash tools, and songs-and-dances. Sullivan-Watts et al. (2012) examined the influence of a professional development program based around commercially 
Gildo GIROTTO JÚNIOR, Carmen FERNANDEZ. Following Early Career Chemistry Teachers: The Development of Pedagogical Content Knowledge from Pre-service to a Professional Teacher

\author{
PROBLEMS \\ OF EDUCATION \\ IN THE $21^{\text {st }}$ CENTURY \\ Volume 55,2013 \\ 70 available inquiry science curricula on the teaching practices of 27 beginning elementary school \\ teachers and their teacher mentors over a 2 year period. \\ In this context, the present study seeks to contribute towards understanding the required \\ knowledge to practice that can be developed from the reflection during the initial training cours- \\ es. Also, from the results, the research can cooperate to identify as the PCK develops during \\ professional experience.
}

\title{
Conclusions and Implications
}

In this research, it was investigated the development of pedagogical content knowledge (PCK) of two chemistry teachers in two different moments: during the pre-service training and after three/two and a half years respectively when both were in-service teachers, with the purpose of recognizing the development of PCK at different moments of the professional experience.

From the analysis carried out it was possible draw a parallel between the classes performed by these teachers in these two moments analysed. It was identified in the collected materials - planning, video records, interviews, CoRe, stimulated recalls - the categories of knowledge that the teachers presented before and after professional practice that document the development of teachers' PCK, thereby helping to strengthen and collaborate with the theoretical models.

The pre-service program allowed these teachers to put into practice their theories of teaching and "try" teaching in all its stages (planning, implementation and evaluation) before acting in a real context.

The results for teachers 1 and 2 revealed a process of attitude changing after the in-service experience. Teachers were able to notice the failures in the lessons they had taught. These failures, were not perceived before. This observation demonstrated that the program had the role of facilitating a process, albeit initial, of reflecting on practice and redesign it.

Considering the class after three/two and a half years in a real context of professional experience, it was verified through CoRe and plannings that there were changes regarding the amount of content, didactic sequence and regarding the curriculum knowledge. Based on this experience teacher realized the difficulties of students with the subject matter, indicating have acquired the knowledge of the learners, which led them to restructure its proposed teaching.

From these considerations, and going back to the initial questions: i.) What are the factors that led to changes in teachers' practice? and ii.) How is the development of pedagogical content knowledge in the early years of professional experience?

It is possible to note that the main factors in changing the classes of the teachers were reflection and practical experience. There was, in the case of T1 a class planning and implementation during the pre-service program. The video-recorded class was analyzed by the teacher in a reflective process, which led him to perceive shortcomings and propose a new teaching plan, a new proposal for the same class.

Taking into account that the teacher performed this analysis just after the class and after three years of the same class, it is possible to infer that T1 had acquired professional experience. Such experience, coupled with reflective practice contributed to the improvement of different categories of knowledge, among which it is highlighted the models and teaching strategies, organization and management of the classroom and knowledge of learners.

This process of planning, executing and redesign agrees with the MPRA model proposed by Shulman (Figure 1).

For T2, is it possible notice changes regarding his practice (changes in planning, changes in teaching strategy) but the reflective process was not so evident. It was noticeable the incorporation of some categories of knowledge, however, is still perceived discrepancies between what the teacher wants and what actually occurs in the classroom.

However, as well as on the teacher 1, teacher 2 presents an experience that made him 
increase his knowledge of the learners and about their difficulties, which contributed to the change in your lesson plan.

By analyzing the Morine Dershimer and Kent model, teaching strategies and discourse in the classroom have direct relation to general pedagogical knowledge. However, the development of the latter also depends both on the reflective process and on the classroom management. It is possible to infer that the lack of knowledge of students' understandings, curriculum and contexts is also specific factors that directly influenced these teachers' PCK. These factors are directly related to professional experience. During the lessons' analysis different aspects are developed in every moment during pre-service training. This process continued during the practical experience and contributed to the development of other knowledge by the teachers.

In a general context, the relationship between theory and practice, as desired in teacher education courses could be promoted from the reflection on practice, as emphasized in the Model of Pedagogical Reasoning and Action of Shulman. Results from this study emphasized that reflection is an important link between theory and practice as it has direct contributions to General Pedagogical Knowledge, Context and Personal Knowledge, thereby influencing the teachers' PCK as is seen at Morine-Dershimer and Kent model.

In this way, it can be inferred that the development of knowledge related to practical yet have been promoted in the course of pre-service training through the experience of planning and conducting an intervention in the classroom and activities that sought to stimulate reflection on action in order to developing PCK. Yet, the professional experience coupled with the reflexive process promoted growth in the PCK of these two teachers, showing a significant increase when it comes to issues related to the knowledge of the learners, the curriculum and the organization and management in the classroom, although the knowledge related to communication and discourse in the classroom is still different from the present intentions in planning and through analysis of interviews.

\section{Future Research and Implications for Teacher Education}

Results from this investigation point to a substantial improvement in PCK for novice teachers in the early years of career. This initial moment, when teachers have just finished the formal education and start themselves in the professional activities seems to be of fundamental relevance to the professional development of teachers.

Data also reveals that each teacher has a different path, the result of its own history, revealing the idiosyncrasies of pedagogical content knowledge.

Despite the increase in PCK should occur naturally through experience, this process can be facilitated by monitoring early career teachers. This could be done with the involvement of these teachers in specific in-service training courses directed to the development of PCK. Based on the presented results, it is clear that changes in the actions of the teachers are not an easy process. It takes a long time in which first the teacher knows and is convinced of actions that need modification in his/her classroom. Secondly, this process needs to be supported to try to advance their actions in the classroom and take a chance on change.

The professional development of teachers needs time and support primarily to happen. Clearly the initial training with little chance of real experience in the classroom does not account for training professionals prepared to meet the challenges of the classroom, although it can provide the necessary framework. In this study we investigated teachers who had a good quality training, who had no difficulty with the specific content and were willing to change. Despite of these extremely favourable conditions it is clear that these teachers still need pairs to assist them in driving new reflections of their actions in the classroom.

The reflective process supported by a collaborative group consisting of teachers of the same discipline and researchers in this area would be a viable way to promote development of PCK. Such a group would resemble the process of residency in the medical school where students already have the responsibilities of a professional, but still has the opportunity to reflect 
Gildo GIROTTO JÚNIOR, Carmen FERNANDEZ. Following Early Career Chemistry Teachers: The Development of Pedagogical Content Knowledge from Pre-service to a Professional Teacher

\section{PROBLEMS \\ OF EDUCATION \\ IN THE $21^{\text {st }}$ CENTURY Volume 55, 2013 \\ 72}

on their performance. Thus it would be possible exchanges of experience among teachers, who experience similar difficulties in the classroom resulting from dealing with the same content and find support in their peers and researchers. A continuous professional development program should follow teachers, especially early career teachers in order to support significant changes in the classroom. Otherwise there is a chance that time and investment in a qualified teacher's initial education be lost for the routines of the everyday life in schools. At the same time while such collaborative groups could collaborate to increase the PCK of early career teachers, it could feed as much research as initial courses with practical problems of the classroom still so far from the initial teacher education in Brazil.

\section{Acknowledgements}

The authors thank the participation of the two investigated teachers who rely on our research beyond the financial support for the research group conducted by Brazilian government agencies CNPq, CAPES and FAPESP.

\section{References}

Abell, S. K. (2006) Research on Science Teacher Knowledge. In: Abell, S.K., \& Lederman, N. (Eds.), Handbook of Science Education. New York, USA: Routledge, 1105-1140.

Abell, S. K. (2008). Twenty Years Later: Does Pedagogical Content Knowledge remain a useful idea?, International Journal of Science Education, 30 (10), 1405-1416.

Cochran-Smith, M. (2001). The outcomes question in teacher education. Teaching and Teacher Education, 17 (5), 527-546.

Cochran, K.F., Deruiter, J.A., King, R.A. (1993). Pedagogical content knowing: an integrative model for teacher preparation. Journal of Teacher Education, 44, 263-272.

Cochran-Smith, M., \& Litle. (1993). S. Inside/outside: Teacher research and knowledge. New York: Teacher's College Press, 1993.

Friedrichsen, P., van Driel, J. H., Abell, S. K. (2010). Taking a Closer Look at Science Teaching Orientations, Science Education, 95 (2), 358-376.

Friedrichsen, P., Abell, S. K., Pareja, E. M., Brown, P. L., Lankford, D. M., Volkmann, M. J. Does teaching experience matter? Examining biology teachers' prior knowledge for teaching in an alternative certification program. Journal of Science Teacher Education. 46 (4), 357 - 383

Girotto-Junior, G. (2011). De licenciando a professor de Química: um olhar sobre o desenvolvimento do Conhecimento Pedagógico do Conteúdo. Master Dissertation. Universidade de São Paulo. Programa de Pós-Graduação Interunidades em Ensino de Ciências.

Grossman, P.L. (1990). The making of a teacher: Teacher knowledge and teacher education, New York (NY), Teacher College Press.

Jang, S. J. (2011). Assessing college students' perceptions of a case teacher's pedagogical content knowledge using a newly developed instrument. Higher Education, 61, 663 -678.

Jang, S. J., Guan, S.Y., Hsieh, H.F. (2009). Developing an instrument for assessing college students' perceptions of teachers' pedagogical content knowledge. Procedia Social and Behavioral Sciences, $1,596-606$.

Käpylä, M., Heikkinen, J., Asunta, J. (2009). Influence of Content Knowledge on Pedagogical Content Knowledge: The case of teaching photosynthesis and plant growth International Journal of Science Education, 31 (10), 1395-1415.

Loughran, J., Mulhall, P., Berry, A. (2004). In search of pedagogical content knowledge in science: developing ways of articulating and documenting Professional practice. Journal of Research in Science Teaching, 41, 4, 370-391.

Loughran, J.; Berry; A.; Mulhall, P. (2006). Understanding and developing science teachers ' pedagogical content knowledge. Rotterdam: Sense Publishers.

Morine-Dershimer, G., \& Kent, T. (2009). The complex nature and sources of teachers' pedagogical knowledge. In: Gess-Newsome, J.; Lederman, N.G. (Eds.), Examining pedagogical content knowledge: the construct and its implications for science teaching. Dordrecht, The Netherlands: Kluwer Academic Publishers. 
Gildo GIROTTO JÚNIOR, Carmen FERNANDEZ. Following Early Career Chemistry Teachers: The Development of Pedagogical Content Knowledge from Pre-service to a Professional Teacher

Mortimer, E., F. \& Scott, P. (2002). Atividade discursiva nas salas de aula de ciências: uma ferramenta sociocultural para analisar e planejar o ensino. Investigações em Ensino de Ciências, 7(3), 283306.

Nilsson, P. (2008). Teaching for understanding: The complex nature of pedagogical content knowledge in pre-service education. International Journal of Science Education, 30 (10) 1281-1299.

Oh, P. S., \& K. S. Kim (2013). Pedagogical Transformations of Science Content Knowledge in Korean Elementary Classrooms. International Journal of Science Education, 35 (9), 1-35.

Orland-Barak, L., \& Yinon, H. (2007). When Theory Meets Practice: Student teachers' reflections on their classroom discourse. Teaching and Teacher Education, 23, 957-969 .

Shulman, L. S. (1986). Those Who Understand: Knowledge Growth in Teaching, Educational Researcher, 15 (2), 4-14.

Shulman, L. S. (1987). Knowledge and Teaching: Foundations of the New Reform, Harvard Educational Review, 57, 1-22.

Sullivan-Watts, B. K., B. Nowicki, B. L., Shim, M.K., Young, B. J. (2012). Sustaining Reform-Based Science Teaching of Preservice and In-service Elementary School Teachers. Journal of Science Teacher Education, 1-27.

van Driel, J. H., De Jong, O., Verloop, N. (2002). The development of preservice chemistry teachers' Pedagogical Content Knowledge, Science Education, 86 (4), 572-590.

van Driel, J. H., Verloop, N., De Vos, W. (1998). Developing Science Teachers' Pedagogical Content Knowledge. Journal of Research in Science Teaching, 35 (6), 673-695.

Vazquez-Bernal, B., Mellado, V., Jiménez-Perez, R., Leñero, C.T. (2012). The process of change in a science teacher's professional development: A case study based on the types of problems in the classroom. Science Education 96 (2), 337-363.

Veal, W. R., \& Makinster, J. G. (1999) Pedagogical Content Knowledge Taxonomies. Electronic Journal of Science Education, 3 (4), 1-18.

Williams, J., Eames, C., Hume, A., Lockley, J. (2012). Promoting Pedagogical Content Knowledge Development for Early Career Secondary Teachers in Science and Technology Using Content Representations. Research in Science \& Technological Education 30 (3), 327-343.

Wilson, S., Shulman, L. Richert, A. E. (1987). 150 different ways of knowing: representations of knowledge in teaching. In Calderhead, .(Ed.). Exploring Teacher Thinking, Sussex: Holt, Rinehart, \& Winston, 104-124.

Advised by Agnaldo Arroio, University of Sao Paulo, Sao Paolo, Brazil

Received: April 07, 2013

Accepted: June 21, 2013

$\begin{array}{ll}\text { Gildo Girotto Júnior } & \text { PhD Student, Interunities Post Graduation Program at University of Sao Paulo, } \\ & \text { Av. Prof Lineu Prestes 748 05508-000 São Paulo - CP 26077 05513-970 São } \\ & \text { Paulo, Brasil. } \\ & \text { Fax: +55 11 3815-5579. } \\ & \text { E-mail: ggirotto@gmail.com } \\ \text { Carmen Fernandez } & \text { Dr., University of Sao Paulo, Chemistry Institute, Department of Chemistry, } \\ & \text { Av. Prof Lineu Prestes 748 05508-000 São Paulo - CP 26077 05513-970 São } \\ & \text { Paulo, Brasil. } \\ & \text { Fax: +55 11 3815-5579. } \\ & \text { E-mail: carmen@iq.usp.br } \\ & \text { Website: www2.iq.usp.br/docente/?id=Carmen }\end{array}$

